\title{
Finite Element Modelling and In Situ Modal Testing of an Offshore Wind Turbine
}

\author{
Erfan Asnaashari ${ }^{1} \cdot$ Andy Morris $^{2} \cdot$ lan Andrew ${ }^{2} \cdot$ Wolfgang Hahn $^{2} \cdot$ Jyoti K. Sinha $^{1}$
}

Received: 10 November 2016 / Revised: 13 December 2016 / Accepted: 21 December 2016 / Published online: 1 August 2018

(c) The Author(s) 2018

\begin{abstract}
Purpose Generating electricity from wind turbines is currently a viable option to meet the electric power requirements in many countries. The structure of offshore wind turbines is constantly subjected to external dynamic loads due to wind, waves and rotor loads due to the rotation of blades. The frequency content of these dynamic loads is in the range of natural frequencies of the wind turbine. Therefore, determining the in situ dynamic characteristics of a wind turbine is very beneficial, as it can lead to further improvements in its design, performance and safety.

Methods In this paper, the dynamics of the structure of an offshore wind turbine is investigated numerically and experimentally. The finite element (FE) model of structural components is developed based on design specifications. The model takes the effect of rotor-nacelle assembly into account by considering its mass and moment of inertias relative to the top centre of the tower. In situ modal tests using impulse excitations were carried out on the actual wind turbine when the rotor blades were not rotating to identify the modal parameters.

Results This paper presents predicted natural frequencies from the FE model based on design conditions and those identified from the modal and ambient excitation tests.

Conclusion It was observed that the first two bending modes are close to the natural frequencies identified experimentally by the in situ modal tests. It was also observed that the in situ modal tests were not able to excite other higher natural frequencies of the structure.
\end{abstract}

Keywords Offshore wind turbines $\cdot$ In situ modal testing $\cdot$ Structural dynamics $\cdot$ Finite element modelling

\section{Introduction}

Erfan Asnaashari

erfan.asnaashari@manchester.ac.uk

Andy Morris

andy.morris@edfenergy.com

Ian Andrew

ian.andrew@edfenergy.com

Wolfgang Hahn

wolfgang.hahn@edfenergy.com

Jyoti K. Sinha

jyoti.sinha@manchester.ac.uk

1 School of Mechanical, Aerospace and Civil Engineering, University of Manchester, Manchester M13 9PL, UK

2 EDF Energy, West Burton, UK
Developing and harvesting alternative sources of energy has become vital over the past few years due to concerns about global warming caused mostly by using fossil fuels for energy production. Some countries have set targets to produce a specific fraction of total required electricity from renewable sources for the next decade to gradually decrease their dependency on fossil fuels. Wind energy is one of the alternatives, which can be converted into electricity by installing wind turbines at locations with consistent winds. Offshore wind farms are rapidly being developed especially in Europe, mainly because larger wind turbines can be placed offshore leading to higher energy production capacity.

The structure of offshore wind turbines is constantly subjected to external dynamic loads due to wind and waves, as well as rotor loads due to the rotation of blades. The frequency content of these dynamic loads is in the range of 
natural frequencies of the wind turbine. Therefore, determining the dynamic characteristics of a wind turbine is very beneficial not only to improve the design and performance, but also to understand their sensitivity to different load cases for structural health monitoring purposes.

Zaaijer [1] investigated the accuracy of several simplified dynamic models for the foundation of offshore wind turbines. The first and second natural frequencies of the support structure for five different wind turbines were obtained from the finite element model and experimental data. The difference between computed and measured natural frequencies was in the order of $0.5-35 \%$ and $3-57 \%$ for the first and second natural frequencies, respectively. The dynamic responses of an offshore wind turbine with jacket foundation were studied by Ong et al. [2] through numerical simulations. Bisoi and Haldar [3] also conducted numerical studies to understand the dynamic behaviour of offshore wind turbines supported on monopiles in clay soil. The tower and monopile were modelled as Euler-Bernoulli beam elements, while the foundation was simulated using nonlinear Winkler model. Adhikari and Bhattacharya [4] also utilised Euler-Bernoulli beam theory to propose a model for characterisation of the dynamic behaviour of offshore wind turbines. Andersen et al. [5] obtained the probability density function of the first natural frequency of an offshore wind turbine with monopile foundation based on a simple model integrating a nonlinear $p-y$ curve for calculation of pile displacement. Their model did not consider soil damping due to material dissipation or wave radiation.

Damgaard et al. [6] carried out experimental investigations to obtain the first bending frequency of an offshore wind turbine in the North Sea. Ten rotor stop tests were conducted to evaluate the dynamic properties of the wind turbine. They also developed a numerical model considering soil damping based on Winkler approach to perform modal analysis and presented the first bending frequency obtained from the numerical model and experiment. A comparison between dynamic responses of monopile, tripod and jacket foundation structures for an offshore wind turbine was made by Shi et al. [7]. In addition to natural frequencies, different responses such as displacement, bending moment and shear force were compared for all the foundations. The modal analysis results showed that marine growth has negligible effect on the natural frequencies. Ibsen [8] equipped a prototype of a bucket offshore wind turbine with accelerometers at different locations to obtain the natural frequencies of the wind turbine for three conditions: idle conditions, turbine without blades and turbine without blades and nacelle. The effect of different conditions on the first two natural frequencies was illustrated.

In this paper, the finite element (FE) model of structural components of an offshore wind turbine is developed based on design specifications to predict the natural frequencies

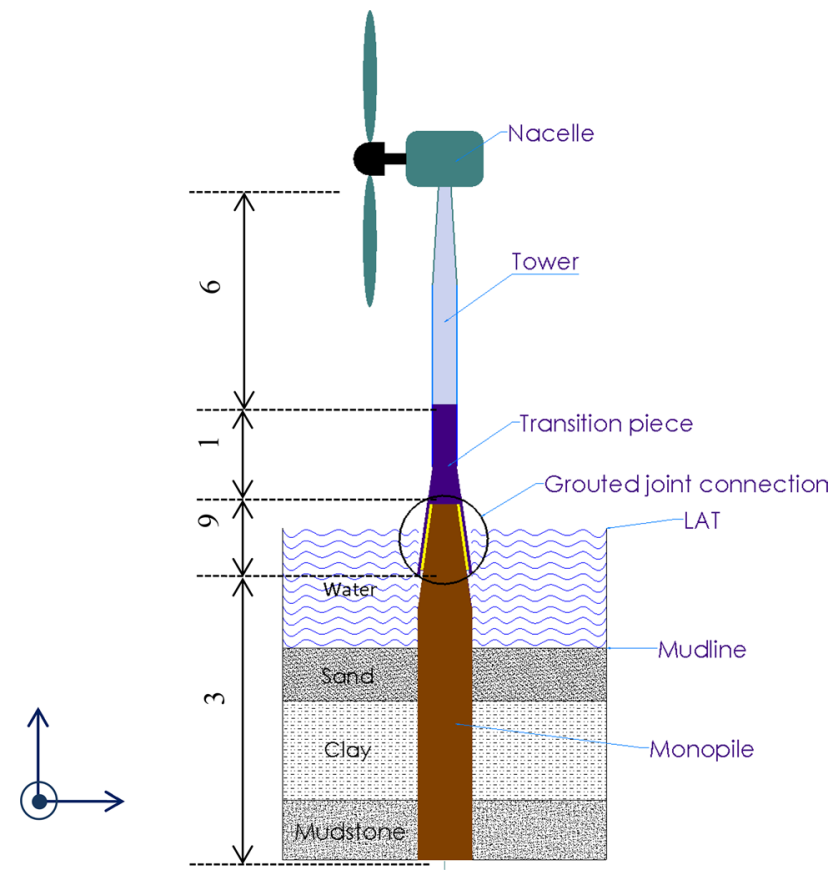

Fig. 1 Schematic view of the offshore wind turbine

Table 1 Specifications of the offshore wind turbine

Turbine name

SWT-2.3-93

Rotor diameter (m)

93

Rated power (MW)

2.3

Hub height (m)

83.15

Water depth (m)

12.52

Pile driven length $(\mathrm{m})$

39.8

Structure diameter (conical) $(\mathrm{m})$

$2.5-4.6$

Wall thickness (mm)

and mode shapes. The model takes the effect of rotor-nacelle assembly into account by considering its mass and moment of inertias relative to the top centre of the tower. Nonlinear support springs obtained from a $p-y$ curve are used to model the interaction between the monopile and the surrounding soil. Also presented in this paper are the results of in situ modal and ambient excitation tests carried out on the actual wind turbine.

\section{Case Study}

A Siemens SWT 2.3 MW offshore wind turbine with monopile foundation is chosen for this case study. The wind turbine is located $1.5 \mathrm{~km}$ off the coast of North-East England. As shown in Fig. 1, the monopile was connected to a conical transition piece which is larger in diameter. The $90 \mathrm{~mm}$ 
annulus between the monopile and transition piece (TP) was filled with an ultrahigh performance grout. The length of the overlap zone for the grouted joint connection is $9 \mathrm{~m}$. The tower was installed on top of the TP through a bolted flange connection to support the rotor-nacelle assembly. The hub height of the turbine is $83.15 \mathrm{~m}$ with respect to the lowest astronomical tide (LAT) and the water depth is $12.52 \mathrm{~m}$. The monopile was driven $40 \mathrm{~m}$ inside the soil. Table 1 summarises the specifications of this case study.

\section{Finite Element Analysis}

This section describes how the components of the turbine shown in Fig. 1 are modelled and assembled together to build a complete FE model. The geometry of the components is created and meshed using open source software called Salome and the analysis is done in Code_Aster which is a mechanical solver.

\section{Rotor-Nacelle Assembly}

The rotor-nacelle assembly (RNA) is modelled as a point mass on top of the tower of the wind turbine. The total mass of RNA including the blades and all the components inside the nacelle is applied according to the specifications provided by the turbine manufacturer. Mass moments of inertia of the RNA relative to the top centre of the tower are also applied to the point mass. These values are presented in Table 2.

\section{Tower and Transition Piece}

Euler-Bernoulli beam element is used to model the entire tower and a part of the transition piece which is above the grouted joint connection (Fig. 1). Each beam element consists of two nodes and each node has three translational and three rotational degrees of freedom and representing a section with constant wall thickness along the tower and transition piece. In total, 211 beam elements are used for modelling this section.

Point and distributed masses of appurtenances such as ladders, platforms and boat landing bumpers on the tower and transition piece are also incorporated into the model. Note that the stiffness contribution of these elements to the wind turbine tower is neglected in the FE model.

Table 2 Mass properties of the RNA

\begin{tabular}{llll}
\hline Total mass $(\mathrm{kg})$ & 134,300 & & \\
Mass moment of inertias $\left(\mathrm{kg} \mathrm{m}^{2}\right)$ & $I_{x x}$ & $I_{y y}$ & $I_{z z}$ \\
& $7.43 \times 10^{6}$ & $1.21 \times 10^{7}$ & $7.34 \times 10^{6}$ \\
\hline
\end{tabular}

\section{Grouted Joint Connection}

The 20 noded quadratic hexahedral element is used to model the grouted connection between the monopile and transition piece which is $9 \mathrm{~m}$ in length. The monopile and transition pieces are made of steel with Young's modulus of $210 \mathrm{GPa}$, density of $7850 \mathrm{~kg} / \mathrm{m}^{3}$ and Poisson's ratio of 0.3 . The grout is modelled as a linear elastic material with Young's modulus of $55 \mathrm{GPa}$, density of $2440 \mathrm{~kg} / \mathrm{m}^{3}$ and Poisson's ratio of 0.19 . As shown in Fig. 2 (left), the inner surface of the transition piece (master) is tied to the outer surface of the grout (slave). Similarly, the inner surface of the grout (master) is tied to the outer surface of the monopile (slave). These connections are made using LIAISON_MAIL command in Code_Aster. The grouted connection is therefore assumed to transfer forces from the transition piece into the monopile as if they are one structure. A total of 4560 hexahedral elements ( 2 segments along the thickness, 40 along the perimeter and 57 along the length) were used altogether for meshing each component of the grouted joint connection.

\section{Monopile and Surrounding Soil}

Similar to the tower and the upper part of the transition piece, Euler-Bernoulli beam elements are used to construct the FE model of the monopile structure below the grouted joint connection. The hydrodynamic mass of water displaced by the submerged monopile and transition piece is calculated and included in the FE model by defining an equivalent density for each submerged element.

The $p-y$ method [9] is employed to model the lateral interaction between the monopile and its surrounding soil. As shown in Fig. 1, the soil in this study consists of three main layers along the driven length of the monopile (27 $\mathrm{m}$ below the mudline); marine sand, clay and mudstone. The beam elements of the monopile are supported by nonlinear springs applied at nodal points between the elements (Fig. 3). These support springs are characterised by one $p-y$ curve at each nodal point. The angle of internal friction of marine sand can be used to obtain the stiffness of springs along this layer. The stiffness per unit length of the clay is equal to the initial slope of the $p-y$ curve as

$k_{\text {clay }}=\frac{p_{\mathrm{u}}\left(y / y_{\mathrm{c}}\right)^{-2 / 3}}{6 y_{\mathrm{c}}}$,

where $y$ is the lateral displacement of the pile and $p_{u}$ is the static ultimate lateral resistance which can be calculated as:

$p_{\mathrm{u}}=\min \left[\left(3 s_{\mathrm{u}}+\gamma X\right) D+J s_{\mathrm{u}} X, 9 s_{\mathrm{u}} X\right]$,

$y_{c}=2.5 \varepsilon_{c} D$, 
Fig. 2 Schematic (left) and FE model (right) of the grouted joint connection
C

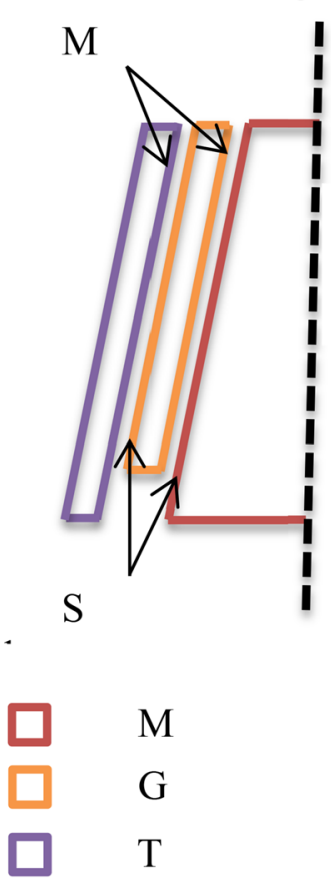

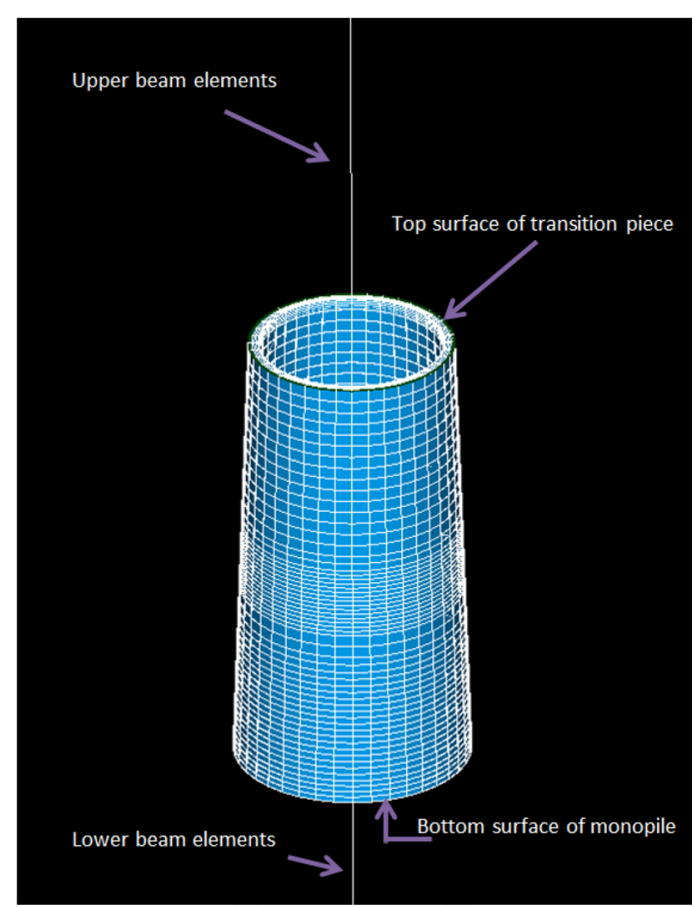
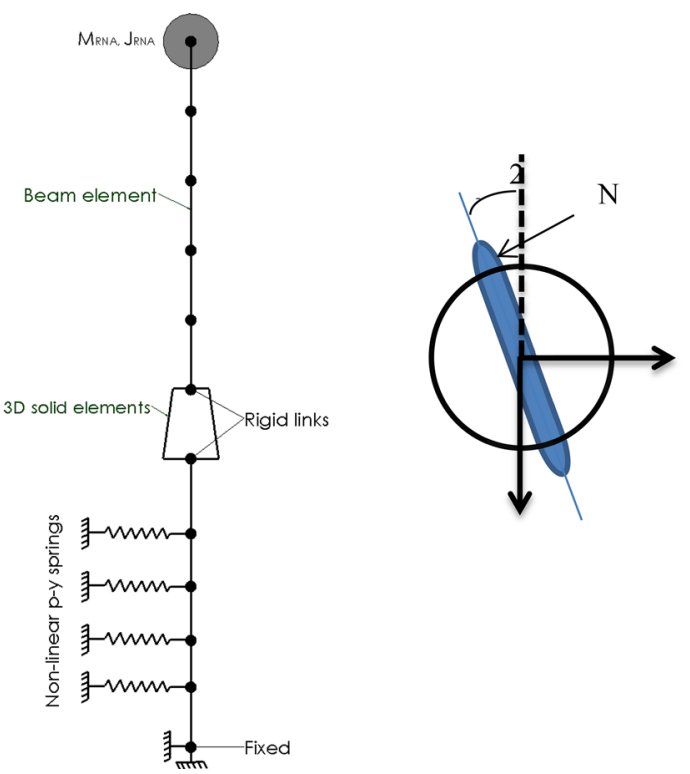

Figure 3 shows the FE model of the complete wind turbine by assembling together all parts from Sects. "Rotor-Nacelle Assembly" to "Monopile and Surrounding Soil". All the degrees of freedom of the node of the monopile at the bottom are restricted. As shown in Fig. 3(right), the nacelle was positioned at an angle of $20^{\circ}$ with respect to the $x$ direction during the in situ experiments; hence, this position of the nacelle is considered in the FE model. The 1-D beam models of the upper and lower parts of the turbine structure are connected to the 3-D model of the middle part through rigid links as shown in Fig. 3. The joint connection using LIAISON_ELEM command is used for these rigid links.

Fig. 3 Schematic view of the FE model (left) and nacelle position (right)

\section{Modal Analysis}

The complete FE model is further used to perform eigenvalue and vector analysis to compute the natural frequencies and mode shapes of the offshore wind turbine. Table 3 presents the computed first and second natural frequencies. 
Table 3 Computed natural frequencies from the FE analysis

\begin{tabular}{lll}
\hline FE model & $x$ direction & $y$ direction \\
\hline 1st bending mode $(\mathrm{Hz})$ & 0.353 & 0.350 \\
2nd bending mode $(\mathrm{Hz})$ & 1.466 & 1.378 \\
\hline
\end{tabular}

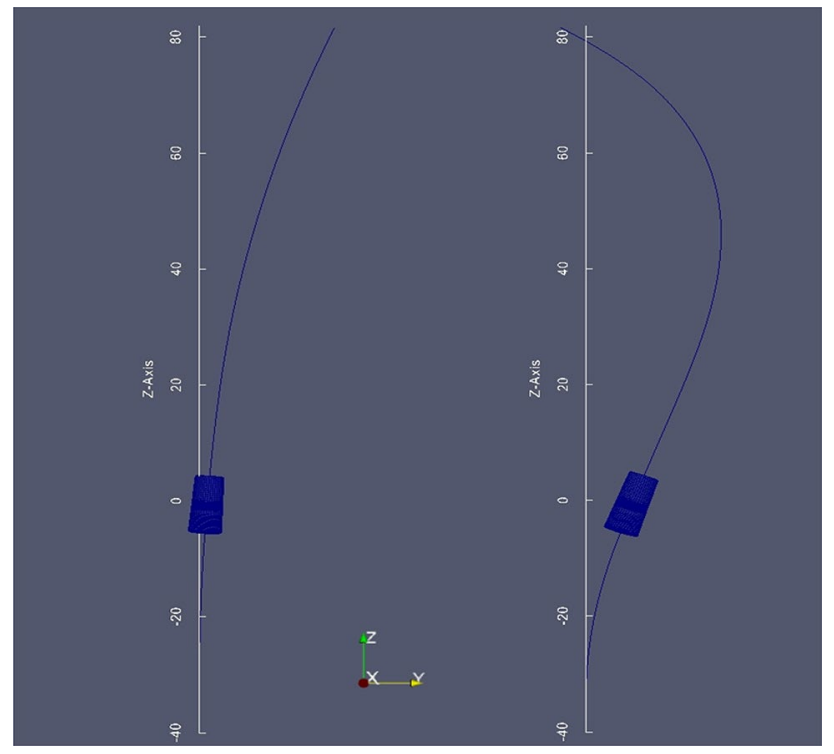

Fig. 4 The first (left) and second (right) bending mode shapes of the wind turbine obtained from the FE analysis

Figure 4 also shows the bending mode shapes of the structure of the wind turbine in one direction.

\section{In Situ Modal Testing}

In situ modal tests using impulse excitations were carried out on the actual wind turbine when the rotor blades were not rotating. The excitation was applied to the structure from inside the transition piece using an instrumented hammer. Low-frequency accelerometers were installed on the inner wall of the transition piece approximately $10.15 \mathrm{~m}$ above LAT in the $x$ and $y$ directions as shown in Fig. 5. Measured forces and accelerations were recorded simultaneously at a sampling rate of $500 \mathrm{~Hz}$ by a data acquisition card connected to a laptop. The frequency response function (FRF) of measured data for both directions is shown in Fig. 6. Table 4 lists the measured natural frequencies obtained from the modal tests.

\section{Ambient Excitation Test}

The acceleration vibration responses of the wind turbine were also recorded under ambient excitation when the rotor was stationary. Such ambient excitation should also excite the turbine natural frequencies. Figure 7 shows the amplitude acceleration spectrum in the $x$ direction due to ambient wind excitation. The peaks observed in the spectrum are also

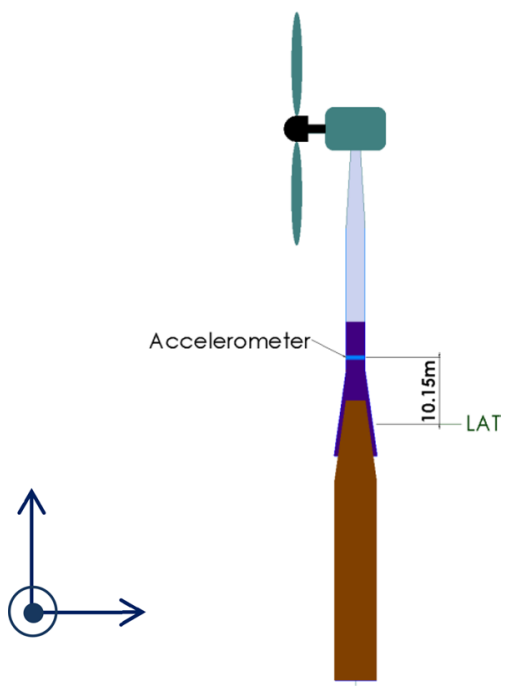

Fig. 5 Location of accelerometers with respect to LAT
Fig. 6 Typical FRF plots obtained from measured acceleration and applied impulsive forces in the $x$ direction (left) and $y$ direction (right)
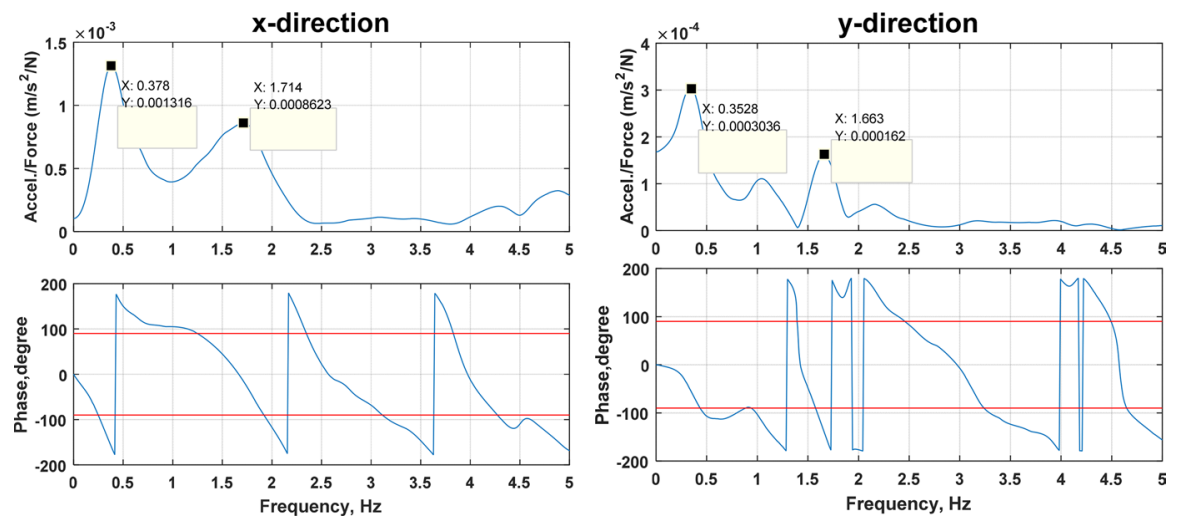
Table 4 Experimentally identified natural frequencies

\begin{tabular}{lll}
\hline Modal tests & $x$ direction & $y$ direction \\
\hline 1st bending mode $(\mathrm{Hz})$ & 0.378 & 0.352 \\
2nd bending mode $(\mathrm{Hz})$ & 1.714 & 1.663 \\
\hline
\end{tabular}

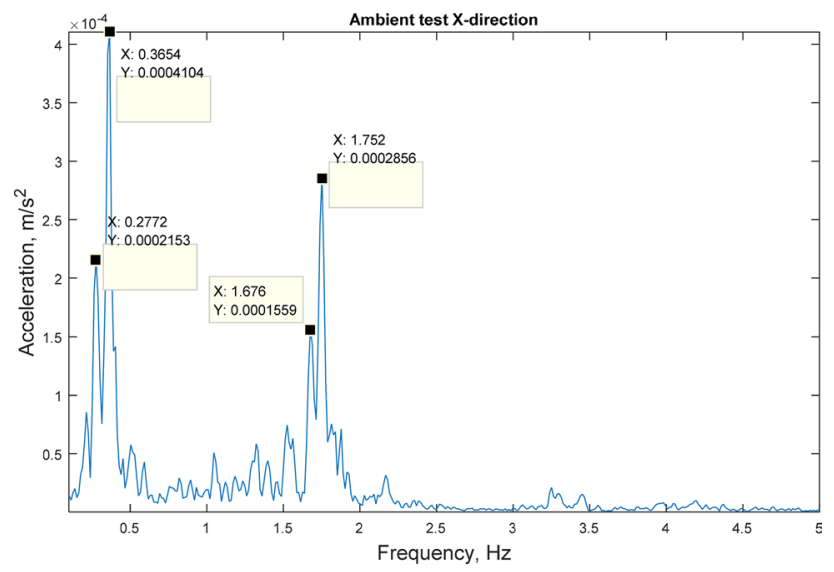

Fig. 7 A typical amplitude acceleration spectrum in the $x$ direction due to o ambient excitation of the wind turbine

close to the natural frequencies identified for the structure in the $x$ and $y$ directions. An additional peak at $0.2772 \mathrm{~Hz}$ may be related to the blade frequency which needs to be verified by carrying out modal tests on the blades.

\section{Conclusion}

The FE model of the wind turbine structure based on the design conditions is used to compute its natural frequencies and mode shapes. It was observed that the first two bending modes are close to the natural frequencies identified experimentally by the in situ modal tests. However, the initial FE model may need to be updated to match the computed natural frequencies to the experimental ones. This may provide better understanding of the turbine dynamics. It was also observed that the in situ modal tests were not able to excite higher natural frequencies of the wind turbine structure and this should be further investigated.

Open Access This article is distributed under the terms of the Creative Commons Attribution 4.0 International License (http://creativeco mmons.org/licenses/by/4.0/), which permits unrestricted use, distribution, and reproduction in any medium, provided you give appropriate credit to the original author(s) and the source, provide a link to the Creative Commons license, and indicate if changes were made.

\section{References}

1. Zaaijer MB (2006) Foundation modelling to assess dynamic behaviour of offshore wind turbines. Appl Ocean Res 28(1):45-57

2. Ong MC, Bachynski EE, Okland OD, Passano E (2014) Dynamic responses of a jacket-type offshore wind turbine using decoupled and coupled models. In: Proceedings of the ASME 2014 33rd international conference on ocean, offshore and arctic engineering OMAE2014 June 8-13, 2014, San Francisco, California, USA

3. Bisoi Swagata, Haldar Sumanta (2014) Dynamic analysis of offshore wind turbine in clay considering soil-monopile-tower interaction. Soil Dyn Earthquake Eng 63:19-35

4. Adhikari S, Bhattacharya S (2012) Dynamic analysis of wind turbine towers on flexible foundations. Shock Vib 19(1):37-56 (American Society of Mechanical Engineers (2014))

5. Andersen LV et al (2012) Natural frequencies of wind turbines on monopile foundations in clayey soils-a probabilistic approach. Comput Geotech 43:1-11

6. Damgaard M, Jacob KFA; Lars Bo I, Andersen, Lars VA (2012) Natural frequency and damping estimation of an offshore wind turbine structure. Proceedings of the twenty-second (2012) international offshore and polar engineering conference. International Society of Offshore \& Polar Engineers 2012, pp 300-307

7. Shi W, Park HC, Chung CW, Kim YC (2011) Comparison of dynamic response of monopile, tripod and jacket foundation system for a 5-MW wind turbine. Proceedings of 21th international offshore and polar engineering conference, Maui, Hawaii, USA

8. Ibsen LB (2008) Implementation of a new foundations concept for offshore wind farms. Nordisk geoteknikermøte nr. 15: NGM 2008, Nordisk geoteknikermøte, Sandefjord. Norsk Geoteknisk Forening, Sandefjord, Norway, pp 19-33

9. DNV-OS-J101 (2010) Design of offshore wind turbine structures. DET NORSKE VERITAS

10. Lymon CR (1997) Analysis of laterally loaded piles in weak rock. J Geotech Geoenviron Eng. https://doi.org/10.1061/ (ASCE)1090-0241(1997)123:11(1010) 